Open Access

\title{
No neuropathological evidence for a direct topographical relation between microbleeds and cerebral amyloid angiopathy
}

Enikö Kövari ${ }^{1 *}$, Andreas Charidimou ${ }^{2}$, François R. Herrmann ${ }^{3}$, Panteleimon Giannakopoulos ${ }^{1}$, Constantin Bouras ${ }^{1,3}$ and Gabriel Gold ${ }^{3}$

\begin{abstract}
Introduction: Cerebral microbleeds correspond to blood breakdown products, including hemosiderin-containing macrophages around small vessels on histological examination. Superficial lobar cerebral microbleeds are increasingly recognized on MRI as a biomarker of cerebral amyloid angiopathy but the direct association between amyloid-laden vessels burden and cerebral microbleeds has yet to be validated neuropathologically. To address this issue, we examined the frequency of histopathologically-defined cerebral microbleeds in different brain regions and their relationship with cerebral amyloid angiopathy in a large autopsy population.

Results: The frontal, parietal and occipital cortex as well as the adjacent white matter and basal ganglia of 113 consecutive autopsies were examined. Cerebral microbleedss were identified on haematoxylin-eosin-stained histological slides, cerebral amyloid angiopathy using anti-amyloid antibody. Cerebral microbleeds were present in $92.9 \%$ of the cases and cerebral amyloid angiopathy in $44.3 \%$ of them. Cerebral microbleeds were more frequent in parietal and frontal lobes followed by the occipital region and basal ganglia. In contrast, cerebral amyloid angiopathy was most frequent in the occipital lobe. There was no significant topographical association between cerebral amyloid angiopathy presence or severity and cerebral microbleeds in any brain region. In lobar areas, cerebral amyloid angiopathy was found in the cortex, predominantly affecting pial arteries and their superficial cortical branches, in contrast to microbleeds which were mainly in the white matter and occurred around deeper arteries and arterioles, including the subcortical segment of long penetrating branches of pial vessels.
\end{abstract}

Conclusions: Our study does not support a direct relation between cerebral microbleeds and cerebral amyloid angiopathy burden at the neuropathological level, raising intriguing questions on the potential pathophysiological mechanisms of cerebral microbleeds in the context of cerebral amyloid angiopathy or other small vessel disease pathology.

\section{Introduction}

Cerebral microbleeds (CMB), an MRI marker of small vessel disease in the brain, are increasingly recognized in healthy elderly individuals and patients with Alzheimer's disease $(\mathrm{AD})$ or cerebrovascular pathologies and vascular cognitive impairement. Radiologically, CMB are defined as small, rounded, hypointense lesions on blood-sensitive MRI sequences, inlcuding T2*-weighed gradient echo

\footnotetext{
* Correspondence: eniko.kovari@hcuge.ch

'Department of Mental Health and Psychiatry, University Hospitals and University of Geneva, 2, chemin du Petit-Bel-Air, 1225 Geneva, Switzerland Full list of author information is available at the end of the article
}

sequences and susceptibility-weighted imaging (SWI) [1, 2]. Limited neuropathological studies indicate that the majority of these radiologically-defined lesions correspond to haemosiderin containing macrophages around small vessels, mainly arterioles [3]. Despite the current hypothesis of $\mathrm{CMBs}$ being a primarily haemorrhagic marker of small vessel injury, the pathophysiological mechanisms and histopathological basis of CMBs remain poorly understood and highly debated [4]. In fact, recent neuropathological observations indicate hemosiderin within macrophages in the brain might not always be indicative of $\mathrm{CMB}$ but rather being associated

\section{Biomed Central}

(c) 2015 Kövari et al. Open Access This article is distributed under the terms of the Creative Commons Attribution 4.0 International License (http://creativecommons.org/licenses/by/4.0/), which permits unrestricted use, distribution, and reproduction in any medium, provided you give appropriate credit to the original author(s) and the source, provide a link to the Creative Commons license, and indicate if changes were made. The Creative Commons Public Domain Dedication waiver (http://creativecommons.org/publicdomain/zero/1.0/) applies to the data made available in this article, unless otherwise stated. 
with iron clearance [5]. In addition, careful pathologic analysis in a population-based autopsy study has demonstrated that a proportion of cerebral microbleeds are associated with microinfarcts [6]. Hence, multiple mechanisms seem likely to contribute to development of microbleeds [7].

Circumstantial evidence supports the hypothesis that hypertensive arteriopathy is mainly associated with deep CMB (i.e. in the basal ganglia, thalami etc.), whereas cerebral amyloid angiopathy (CAA) is notably related to superficial, lobar CMBs [3, 5, 8-15]. Since CAA pathology is not directly visible on neuroimaging, the in vivo clinical diagnosis of CAA is currently based on the recognition of multiple strictly lobar CMB on MRI, as a putative marker of the disease $[9,16-19]$. This approach and more importantly the exact mechanism by which CAA gives rise to CMB has not been explored in neuropathological studies. Only a handful of cases have been examined for histopathological confirmation of MRI data $[3,12,14,20,21]$. Even fewer studies have examined the direct neuropathological correlation between CAA and lobar CMB [22].

\section{Materials and methods}

The study received approval from the Ethics Committee of the University of Geneva. Brains were obtained by autopsies from the Department of Internal Medicine, Rehabilitation and Geriatrics, Division of Geriatrcs, and the Department of Readaptation and Palliative Medicine, University Hospitals, Geneva. We included 113 consecutive brain autopsies - 33 cases with dementia - performed between August 2012 to August 2014. For neuropathological analysis, tissues blocks were systematically taken in all cases from the hippocampus, inferior temporal cortex (Brodmann area 20), frontal cortex (Brodmann area 9), parietal cortex (Brodmann area 40), occipital cortex (Brodmann areas 17 and 18) and the basal ganglia at the level of the anterior commissure of the left cerebral hemisphere. Paraffinembedded $14-\mu \mathrm{m}$-thick adjacent sections were stained with haematoxylin-eosin (HE), cresyl-violet (Nissl) and using anti-A $\beta$ monoclonal antibodies (4G8; Signet Laboratories, Dedham, MA, USA; 1:2000) and anti-tau (AT8; Pierce Biotechnology, Rockford, IL, USA; 1:1000) consecutively. The severity of AD-related neuropathological changes was defined using the Braak stages for neurofibrillary tangles (NFTs) and the Thal phases for amyloid plaque deposition $[23,24]$ in the medial temporal lobe.

The presence or absence of CMB was noted on HEstained histological sections. A case was considered positive for CMBs when haemosiderin-laden macrophages were present around at least one vessel, in one or more of the sampled regions. The presence or absence of CAA was determined on anti-A $\beta$-antibody-stained sections. In the basal ganglia only grey matter lesions but no lesions in the surrounding white matter or internal capsule were taken into consideration.

On a four-level grading system CAA severity and burden was evaluated based on the existing systems of Vonsattel and al. [25] and Olichney et al. [26]. The average severity of amyloid deposition in the vessels wall and the extent of the lesions were taken in account as follows: grade 0 was noted in the absence of CAA. In grade 1 only a thin amyloidpositive rim was observed around smooth muscle cells of the otherwise normal media layer of scattered vessels (Fig. 1a, d). Grade 2 showed more extensive depositions

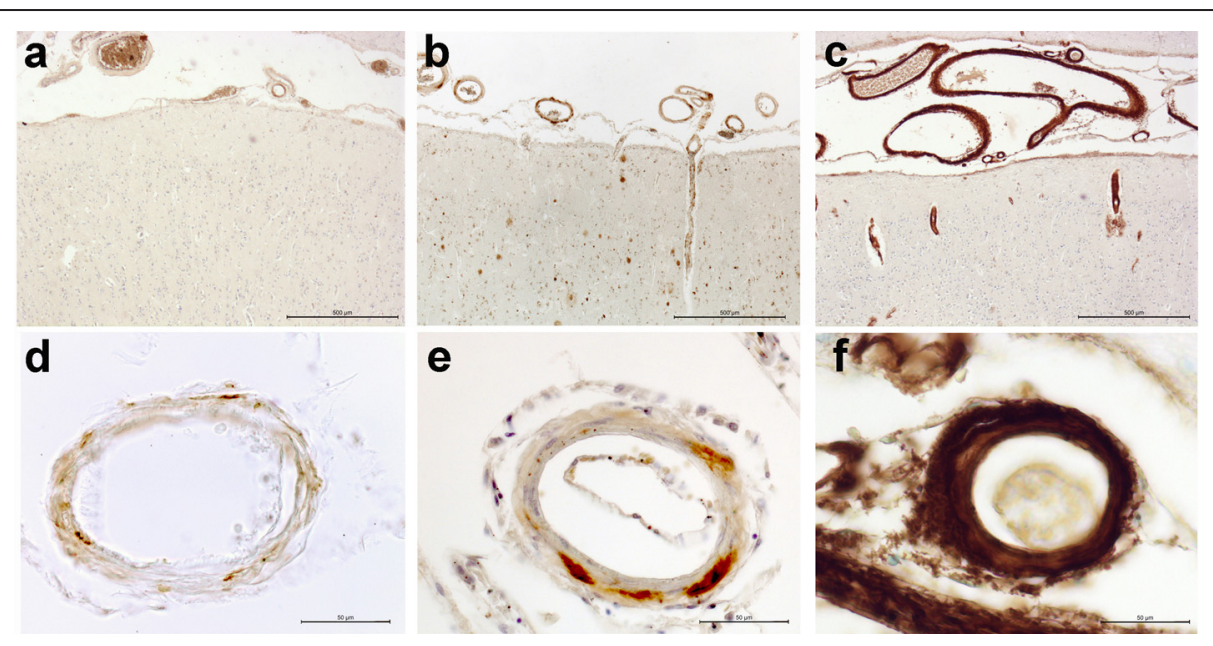

Fig. 1 Grading of the severity of amyloid angiopathy. Grade 1: scattered amyloid deposition presenting as a thin rim of A $\beta$ positive fibers around the smooth muscle cell of the media (a and $\mathbf{d}$ ); Grade 2: more extensive presence of amyloid in the vessel's wall with focal replacement of the muscular layer (b and $\mathbf{e}$ ); Grade 3: complete destruction of the wall by the severe amyloid deposition, present in most pial and superficial vessels

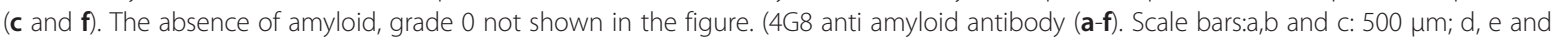
f: $50 \mu \mathrm{m})$ 
and the medial layer of the vessels replaced by amyloid (Fig. 1b, e). Grade 3 was characterized by circumferential, severe destruction of the wall by amyloid deposition, with most vessels being affected (Fig. 1c, f). Separately, in each case the exact localisation (meningeal or meningo-cortical) as well as the presence and severity of capillary amyloid deposition [27] was noted as recently proposed by Love et al. [28]. The severity of capillary amyloid deposition was defined on ground of its extension.

\section{Statistical analysis}

Group comparisons were performed using Fisher's exact test for dichotomous variables, Student $t$-test for continuous variables or Wilcoxon-Mann-Whitney $u$-test for ordinal variables as appropriate. Multivariable logistic regression analyses were used to evaluate the association between the dependent variables (CMB or CAA) within each brain area and the independent variables (Braak NFT staging, $A \beta$ deposition staging) with and without adjustment for age. Significance level was set at 0.05 and all tests of significance were two-tailed. All statistical analyses were carried out using Stata version 13.1 (Stata Corporation, College Station, TX, USA).

\section{Results}

Our study sample consisted of 64 women and 49 men (mean age: $81.1 \pm 10.8$ years; age range: $51-99$ years; Table 1). Macroscopic intracerebral haemorrhage was found only in two cases, both in subtentorial regions (brainstem and cerebellum). Lobar CMB were found in $92.9 \%$ of the study population whereas CAA was present in $44.3 \%$ of the cases. In the different diagnostic groups distinct prevalences of CAA was observed, the highest in the 25 cases with AD (Braak stage $\geq 4 ; 14$ pure $\mathrm{AD}$ and 11 associated with vascular encephalopathy - Table 2). The prevalence of CMBs was highest in the parietal (84.1\%) and frontal lobes (76.9\%), followed by the occipital area (46.9\%). In contrast, CAA was more frequent in the occipital lobe (38.9\%), compared to frontal

Table 1 Demographic data

\begin{tabular}{lcc}
\hline & Number of cases & Mean age \pm SD \\
\hline Total (M/F) & $113(49 / 64)$ & $81.1 \pm 10.8$ \\
Non demented & 80 & $79.1 \pm 11.7$ \\
Dementia & 33 & $85.7 \pm 6.4$ \\
AD & 14 & $84.8 \pm 7.1$ \\
VaD & 5 & $88.2 \pm 3.6$ \\
Mixed D & 11 & $86.2 \pm 7.1$ \\
LBD & 3 & $84.3 \pm 6.1$ \\
\hline
\end{tabular}

$A D$ Alzheimer's disease, $V a D$ vascular dementia, Mixed $D$ mixed (AD and vascular) dementia, $L B D$ Lewy body dementia
(30.9\%) and parietal areas (28.3\%). Parenchymal (cortical) CAA was most frequent in the occipital area, in $72.3 \%$ of CAA cases (Table 3).

Basal ganglia CMBs were identified in $46.2 \%$ of the cases. CAA in the basal ganglia was seen in 1 case only. With the exception of 3 cases, basal ganglia CMBs were accompagnied by lobar CMBs in at least one cortical area.

Capillary amyloid deposition was observed in 12 subjects (24\% of CAA positive cases and $10 \%$ of the total population). Seven cases showed moderate-severe, 5 mild amyloid deposition. Capillary amyloid deposition (type 1) [27] or its severity did not influence the presence or absence of CMB (frontal lobe: $p=0.209$; parietal lobe: $p=0.379$; occipital lobe: $p=0.736$ ).

There was no significant association between the presence of CAA and lobar CMB either overall (Fisher's exact $p=0.463$ ) or separately in each brain region examined. CAA, was associated with age $(p<0.001)$ but CMB were not. CAA in the white matter was rare (5 cases, $4.4 \%$ ) and only 8 cases $(7 \%)$ exhibited intracortical CMBs, indicating that these lesions occur in different compartments of the brain (Fig. 2). On close topographical analysis, CAA and CMB involved different types or different segments of vessels. CAA was mainly present in the pial arteries and their superficial short perforating branches, and less often in the superficial (intra-cortical) segments of long branches, e.g. in the surface of the brain or in the superficial cortical layers. In contrast, lobar microbleeds were detected in the adjacent white matter, often at the cortical-white matter junction (i.e. juxtacortical at the level of and around the long branches of pial vessels and the medullary arteries) or around deeper arteries and arterioles (Fig. 3).

We explored whether $\mathrm{CMB}$ presence in the underlying juxtacortical white matter was related to leptomeningeal/ cortical CAA. We found no association in any of the studied regions for either the presence (Fisher's exact test $p=0.628$; 0.776; and 0.701) or severity (Mann-Whitney

Table 2 Frequencies of CAA and CMB and mean CAA severities depending on neuropathological diagnosis

\begin{tabular}{lcccc}
\hline $\begin{array}{l}\text { Neuropathologial } \\
\text { diagnosis }\end{array}$ & $\begin{array}{l}\text { No of } \\
\text { cases }\end{array}$ & $\begin{array}{l}\text { Prevalence of } \\
\text { CAA (\%) }\end{array}$ & $\begin{array}{l}\text { Prevalence of } \\
\text { CMB (\%) }\end{array}$ & $\begin{array}{l}\text { Mean } \\
\text { severity of } \\
\text { CAA }\end{array}$ \\
\hline AD & 14 & 71 & 78 & 1.5 \\
Va & 29 & 55 & 93 & 1.2 \\
AD + Va & 11 & 63 & 91 & 1.7 \\
C & 34 & 38 & 91 & 0.7 \\
Others & 25 & 16 & 100 & 0.5 \\
\hline
\end{tabular}

$A D$ Alzheimer's disease, $V a$ vascular encephalopathy, $A D+V a$ mixed (AD-type and vascular encephalopathy), $C$ no brain lesions, Others = any type of Lewy body pathology as Parkinson's disease, Lewy body dementia - 8 cases, or multiple system atrophy (1 case), amyotrophic lateral sclerosis (2 cases) or brain metastases (14 cases) 
Table 3 Distribution of CAA and the proportion of meningeal and meningocortical CAA in the different brain regions

\begin{tabular}{lccc}
\hline $\begin{array}{l}\text { Region (total } \\
\text { number of CAA) }\end{array}$ & $\begin{array}{l}\text { CAA (\%) of } \\
\text { the total } \\
\text { population }\end{array}$ & mx_CAA (\%) & mx_cx_CAA (\%) \\
\hline Frontal (35) & 30.9 & $18(51.4)$ & $17(48.6)$ \\
Parietal (32) & 28.3 & $13(40.6)$ & $19(59.4)$ \\
Occipital (44) & 38.9 & $12(27.3)$ & $32(72.3)$ \\
\hline
\end{tabular}

Mx_CAA CAA present only in meningeal vessels, $m x_{-} c x_{-}$CAA CAA present in both meningeal and cortical vessels $p=0.326 ; 0.656 ; 0.628)$ of leptomeningeal/cortical CAA in frontal, parietal and occipital lobes, respectively.

\section{Discussion}

Our report is the first systematic neuropathological study in a large autopsy series directly examining the relationship between $\mathrm{CMB}$ and $\mathrm{CAA}$, including their anatomical distribution. According to our primary findings there is no association between the overall presence and burden of CAA and histopathologically-defined CMB presence, nor
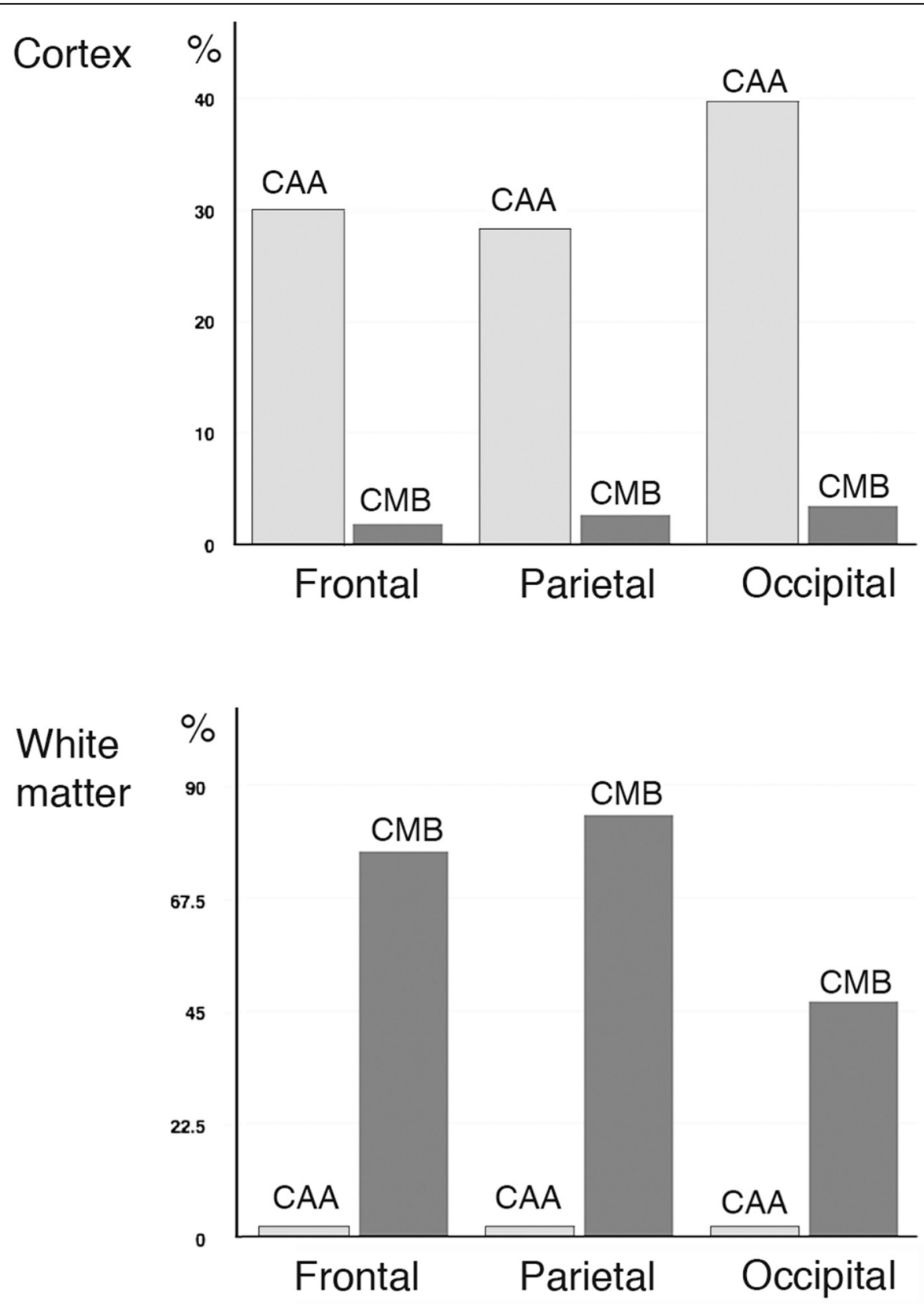

Fig. 2 Percentage of cases with CMB and CAA. Distribution of CAA and CMB in the cortex and subcortical white matter. Note that CMB and CAA occur in different sectors of the brain (see text for details) 


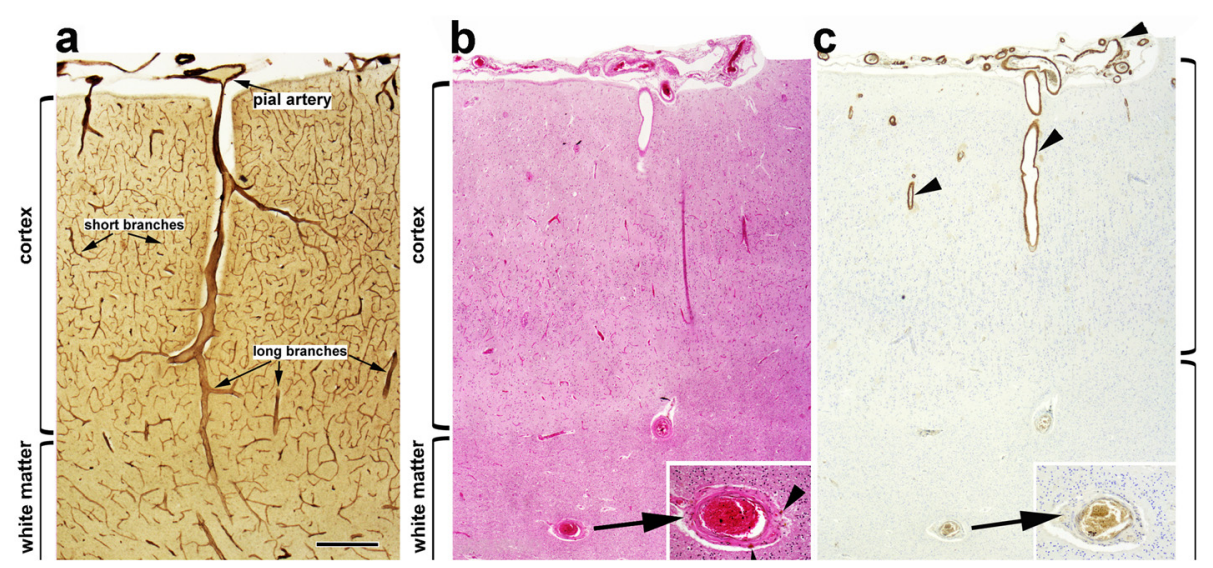

Fig. 3 Topographical distribution of CMB and CAA. a Normal microvascular architecture of the cerebral cortex and underlying white matter. $\mathbf{b}$ Hemosiderin-laden macrophages (arrowheads) around small arteries of the white matter. c Amyloid angiopathy (arrowheads) in the pial and superficial cortical branches. a: modified Gallyas silver-impregnation; $\mathbf{b}$ : haematoxylin-eosin staining; $\mathbf{c}$ immunohistochemistry with anti-amyloid antibody 4G8. Scale bar on A: $500 \mu \mathrm{m}$ )

concerning their topography within brains. These results raise interesting questions about the precise mechanisms underlying the development of most microbleeds.

We report a high frequency of CAA which is in line with earlier results from our group [29] and other published data from consecutive autopsy cases that used immunohistochemical detection methods [30, 31]. CMBs were more frequently detected in the current cohort compared to other autopsy based studies. This may be related in part to strict adherence to the neuropathological definition and, close attention to the presence of CMBs since their identification was a main aim of the study. Fisher et al. reported a CMB prevalence of $66 \%$ in 33 autopsy cases [32]. In a large population-based autopsy study of older people with intracerebral hemorrhage $(n=300)$, Tanskanen et al. investigated the presence and extent of CMBs [6] and found them in $67.3 \%$ of the cases. This confirms that neuropathological-defined CMB on histologic examination are much more common compared to rediologicallydefined CMBs.

Our results do not confirm a direct neuropathological relationship between lobar CMB and CAA. This is consistent with a recent study of cerebellar microbleeds by de Reuck et al. who reported that CMB were related to atherosclerosis but not to CAA [33]. This contrasts with the bulk of the neuroimaging-based literature [15, 34-37]. In the population-based Rotterdam scan study [15] there was a strong association between strictly lobar (but not deep) CMBs and APOE $\varepsilon 4$ (later confirmed in a meta-analysis [38]), consistent with the well-known relation of this allele with CAA [1]. The APOE $\varepsilon 2$ allele is also of major importance in CAA-related cerebral hemorrhage [39], although its exact role in CMBs mechanisms is still unexplored in the literature. In another healthy elderly cohort, multiple lobar CMBs were recently found to be associated with higher amyloid- $\beta$ burden, as detected by $11 \mathrm{C}$-Pittsburgh Compound B positron emission tomography (PiB-PET) imaging [40]. Co-registered PiB-PET imaging has shown that lobar CMB hotspots preferentially correspond to locations with increased amyloid concentration [41]. However, PiB-PET has poor spatial resolution and, similar to the other clinical-radiological studies on the topic, cannot reliably resolve the location of parenchymal and vascular amyloid- $\beta$. Thus, histopathological validation and studies on the pathogenesis of CMB at the level of individual vessel pathology are crucial to supplement imaging studies.

One of our main results is the spatial dissociation between CMB and CAA that was observed on close neuropathological examination. CAA predominantly affected pial arteries, and their superficial cortical branches; in contrast, $\mathrm{CMB}$ were found at the level of white matter cortical perforating vessels or medullary arteries. This is consistent with a study of $8 \mathrm{AD}$ patients by Schrag and colleagues [12] who reported that the majority of pathologically-defined CMB occurred near the cortical ribbon in the adjacent white matter. In a larger autopsy series, Tanskanen et al. [6] mentioned that even in the simultaneous presence of $\mathrm{CMB}$ and CAA on the same histological slide, CMBs were not always situated around amyloid-laden vessels. Fisher et al. [32] in their series of 33 cases also report the occurrence of $\mathrm{CMB}$ around vessels without any evidence of amyloid deposition. The neuropathological studies that report a direct relationship between CAA and CMB are scarce and based on a very small number of subjects [12, 21]. In a series of 6 autopsy cases with CAA that included 3 cases with high CMB counts, 2 cases with a low number of $C M B$ and 1 case without any microbleed, Greenberg and collaborators observed a thicker amyloid positive vessel wall in subjects with 
numerous microbleeds [21]. Schrag et al. [12] performed postmortem MRI in $8 \mathrm{AD}$ autopsy cases and found advanced CAA in 6 of them, with amyloid deposion in the vessel's wall near microbleeds.

Our study has several limitations which should taken into account. It was peformed in a hospital based autopsy series with a high mean age, and may represent a more severely affected population than community based samples, where the frequency of $\mathrm{CMB}$ might be lower. Also, we report on the presence or absence of $\mathrm{CMB}$,including very small lesions, clearly identifiable on neuropathological examination but probably very hard to visualize on conventional MRI. Finally, we have analyzed the relation between lobar CMB and CAA pathology, regardless of the concurrent presence in the same brain of $\mathrm{CMB}$ in deep gray matter or brainstem $\mathrm{CMB}$, which might indicate the presence and contribution of non-CAA small vessels disease pathology in the pathophysiology of microbleeds.

\section{Conclusions}

Our study does not intend to underemphasise the clinical importance of the in vivo detection of MRI-defined CMB or critically analyze the current MRI Boston diagnostic criteria, since it does not contain either MRI or clinical data. However, our neuropathological data provide evidence that the assumed link between CAA and lobar CMB, an MRI derived concept, does not seem to have a clear direct neuropathological validity, at least at the level of individual vessel pathology. Of note, there seems to be a dissconnection of the MRI-definition vs. pathological definition of CMBs. For example, CMBs detected on $3 \mathrm{~T}$ blood-sensitive sequences are likely mostly very much larger than the few hemosiderin deposits that are observed microscopically. The literature on CMBs overwhelmingly emphasizes them as a haemorrhagic signature and stress the hemorrhagic risk associated with microbleeds. However, some authors have postulated that parenchymal iron deposits may arise both from haemorrhagic and ischaemic mechanisms. Therefore the field is using the same terminology to describe what may be different types of lesion - a more definitive radiographic imaging marker, with as-yet uncertain pathologic basis [7]. Further studies will need to explore additional potential pathophysiological mechanisms that could lead to the occurrence of $\mathrm{CMB}$, including direct imagingpathologic correlation studies and ex-vivo MRI data.

\section{Competing interests}

The authors declare that they have no competing interest.

\section{Authors' contributions}

$E K, C B, P G$ and GG designed the study. EK and CB did data collection and histological analyses. FRH performed statistical analyses. All authors participated in the data interpretation. EK wrote the paper. GG, PG and AC provided critical reading of the manuscript. All authors approved the final version of the manuscript.

\section{Acknowledgements}

Authors thank M. Demiri and P. Lovero for expert technical assistance This work was supported by Swiss National Foundation grant SNF 320030_159990.

\section{Author details}

${ }^{1}$ Department of Mental Health and Psychiatry, University Hospitals and University of Geneva, 2, chemin du Petit-Bel-Air, 1225 Geneva, Switzerland. ${ }^{2}$ Massachusetts General Hospital Stroke Research Center, Harvard Medical School, 175 Cambridge Street, Suite 300, Boston, MA 02114, USA.

${ }^{3}$ Department of Internal Medicine, Rehabilitation and Geriatrics, University Hospitals and University of Geneva, 3 chemin du Pont-Bochet, 1226 Thônex, Switzerland.

Received: 28 July 2015 Accepted: 29 July 2015

Published online: 14 August 2015

\section{References}

1. Charidimou A, Gang Q, Werring DJ (2012) Sporadic cerebral amyloid angiopathy revisited: recent insights into pathophysiology and clinical spectrum. J Neurol Neurosurg Psychiatry 83:124-137

2. Greenberg SM, Vernooij MW, Cordonnier C, Viswanathan A, Al-Shahi Salman R, Warach S, Launer LJ, Van Buchem MA, Breteler MM, Microbleed Study G (2009) Cerebral microbleeds: a guide to detection and interpretation. Lancet Neurol 8:165-174

3. Fazekas F, Kleinert R, Roob G, Kleinert G, Kapeller P, Schmidt R, Hartung HP (1999) Histopathologic analysis of foci of signal loss on gradient-echo T2*-weighted MR images in patients with spontaneous intracerebral hemorrhage: evidence of microangiopathy-related microbleeds. AJNR. Am J Neuroradiol 20:637-642

4. Attems J, Jellinger K, Thal DR, Van Nostrand W (2011) Review: sporadic cerebral amyloid angiopathy. Neuropathol Appl Neurobiol 37:75-93

5. Janaway BM, Simpson JE, Hoggard N, Highley JR, Forster G, Drew D, Gebril OH, Matthews FE, Brayne C, Wharton SB, Ince PG, Function MRCC, Ageing Neuropathology S (2014) Brain haemosiderin in older people: pathological evidence for an ischaemic origin of magnetic resonance imaging (MRI) microbleeds. Neuropathol Appl Neurobiol 40:258-269

6. Tanskanen M, Makela M, Myllykangas L, Rastas S, Sulkava R, Paetau A (2012) Intracerebral hemorrhage in the oldest old: a population-based study (vantaa 85+). Front Neurol 3:103

7. Fisher M (2014) Cerebral microbleeds: where are we now? Neurology 83:1304-1305

8. Greenberg SM (1998) Cerebral amyloid angiopathy: prospects for clinical diagnosis and treatment. Neurology 51:690-694

9. Greenberg SM, Al-Shahi Salman R, Biessels GJ, van Buchem M, Cordonnier C, Lee JM, Montaner J, Schneider JA, Smith EE, Vernooij M, Werring DJ (2014) Outcome markers for clinical trials in cerebral amyloid angiopathy. Lancet Neurol 13:419-428

10. Rosand J, Muzikansky A, Kumar A, Wisco JJ, Smith EE, Betensky RA, Greenberg SM (2005) Spatial clustering of hemorrhages in probable cerebral amyloid angiopathy. Ann Neurol 58:459-462

11. Rosenblum WI (2008) Fibrinoid necrosis of small brain arteries and arterioles and miliary aneurysms as causes of hypertensive hemorrhage: a critical reappraisal. Acta Neuropathol 116:361-369

12. Schrag M, McAuley G, Pomakian J, Jiffry A, Tung S, Mueller C, Vinters HV Haacke EM, Holshouser B, Kido D, Kirsch WM (2010) Correlation of hypointensities in susceptibility-weighted images to tissue histology in dementia patients with cerebral amyloid angiopathy: a postmortem MRI study. Acta Neuropathol 119:291-302

13. Tanaka A, Ueno Y, Nakayama Y, Takano K, Takebayashi S (1999) Small chronic hemorrhages and ischemic lesions in association with spontaneous intracerebral hematomas. Stroke 30:1637-1642

14. Tatsumi S, Shinohara M, Yamamoto T (2008) Direct comparison of histology of microbleeds with postmortem MR images: a case report. Cerebrovasc Dis 26:142-146

15. Vernooij MW, van der Lugt A, Ikram MA, Wielopolski PA, Niessen WJ, Hofman A, Krestin GP, Breteler MM (2008) Prevalence and risk factors of cerebral microbleeds: the Rotterdam Scan Study. Neurology 70:1208-1214

16. Charidimou A, Jager RH, Peeters A, Vandermeeren Y, Laloux P, Baron JC, Werring DJ (2014) White matter perivascular spaces are related to cortical superficial siderosis in cerebral amyloid angiopathy. Stroke 45:2930-2935 
17. Knudsen KA, Rosand J, Karluk D, Greenberg SM (2001) Clinical diagnosis of cerebral amyloid angiopathy: validation of the Boston criteria. Neurology 56:537-539

18. Linn J, Halpin A, Demaerel P, Ruhland J, Giese AD, Dichgans M, van Buchem MA, Bruckmann H, Greenberg SM (2010) Prevalence of superficial siderosis in patients with cerebral amyloid angiopathy. Neurology 74:1346-1350

19. Viswanathan A, Greenberg SM (2011) Cerebral amyloid angiopathy in the elderly. Ann Neurol 70:871-880

20. De Reuck J, Auger F, Cordonnier C, Deramecourt V, Durieux N, Pasquier F, Bordet R, Maurage CA, Leys D (2011) Comparison of 7.0-T T(2)*-magnetic resonance imaging of cerebral bleeds in post-mortem brain sections of Alzheimer patients with their neuropathological correlates. Cerebrovasc Dis 31:511-517

21. Greenberg SM, Nandigam RN, Delgado P, Betensky RA, Rosand J, Viswanathan A, Frosch MP, Smith EE (2009) Microbleeds versus macrobleeds: evidence for distinct entities. Stroke 40:2382-2386

22. Martinez-Ramirez S, Greenberg SM, Viswanathan A (2014) Cerebral microbleeds: overview and implications in cognitive impairment. Alzheimers Res Ther 6:33

23. Braak H, Braak E (1991) Neuropathological stageing of Alzheimer-related changes. Acta Neuropathol 82:239-259

24. Thal DR, Rüb U, Orantes M, Braak H (2002) Phases of A $\beta$-deposition in the human brain and its relevance for the development of AD. Neurology 58:1791-1800

25. Vonsattel JP, Myers RH, Hedley-Whyte ET, Ropper AH, Bird ED, Richardson EP Jr (1991) Cerebral amyloid angiopathy without and with cerebral hemorrhages: a comparative histological study. Ann Neurol 30:637-649

26. Olichney JM, Hansen LA, Hofstetter CR, Grundman M, Katzman R, Thal L (1995) Cerebral infarction in Alzheimer's disease is associated with severe amyloid angiopathy and hypertension. Arch Neurol 52:702-708

27. Thal DR, Ghebremedhin E, Rüb U, Yamaguchi H, Del Tredici K, Braak H (2002) Two types of sporadic cerebral amyloid angiopathy. J Neuropathol Exp Neurol 61:282-293

28. Love S, Chalmers K, Ince P, Esiri M, Attems J, Jellinger K, Yamada M, McCarron M, Minett T, Matthews F, Greenberg S, Mann D, Kehoe PG (2014) Development, appraisal, validation and implementation of a consensus protocol for the assessment of cerebral amyloid angiopathy in post-mortem brain tissue. Am J Neurodegener Dis 3:19-32

29. Kövari E, Herrmann FR, Hof PR, Bouras C. The relationship between cerebral amyloid angiopathy and cortical microinfarcts in brain ageing and Alzheimer's disease. Neuropathol Appl Neurobiol. 2012;39:498-509

30. Jellinger KA, Lauda F, Attems J (2007) Sporadic cerebral amyloid angiopathy is not a frequent cause of spontaneous brain hemorrhage. Eur J Neurol 14:923-928

31. Launer LJ, Petrovitch $H$, Ross GW, Markesbery W, White LR (2008) AD brain pathology: vascular origins? Results from the HAAS autopsy study. Neurobiol Aging 29:1587-1590

32. Fisher M, French S, Ji P, Kim RC (2010) Cerebral microbleeds in the elderly: a pathological analysis. Stroke 41:2782-2785

33. De Reuck JL, Deramecourt V, Auger F, Durieux N, Cordonnier C, Devos D, Defebvre L, Moreau C, Capparos-Lefebvre D, Pasquier F, Leys D, Maurage CA, Bordet R (2015) The significance of cortical cerebellar microbleeds and microinfarcts in neurodegenerative and cerebrovascular diseases. A post-mortem 7.0-tesla magnetic resonance study with neuropathological correlates. Cerebrovasc Dis 39:138-143

34. Cordonnier C, Al-Shahi Salman R, Wardlaw J (2007) Spontaneous brain microbleeds: systematic review, subgroup analyses and standards for study design and reporting. Brain 130:1988-2003

35. Dierksen GA, Skehan ME, Khan MA, Jeng J, Nandigam RN, Becker JA, Kumar A, Neal KL, Betensky RA, Frosch MP, Rosand J, Johnson KA, Viswanathan A, Salat DH, Greenberg SM (2010) Spatial relation between microbleeds and amyloid deposits in amyloid angiopathy. Ann Neurol 68:545-548

36. Mesker DJ, Poels MM, Ikram MA, Vernooij MW, Hofman A, Vrooman HA, van der Lugt A, Breteler MM (2011) Lobar distribution of cerebral microbleeds: the Rotterdam Scan Study. Arch Neurol 68:656-659

37. Shoamanesh A, Martinez-Ramirez S, Oliveira-Filho J, Reijmer Y, Falcone GJ, Ayres A, Schwab K, Goldstein JN, Rosand J, Gurol ME, Viswanathan A, Greenberg SM (2014) Interrelationship of superficial siderosis and microbleeds in cerebral amyloid angiopathy. Neurology 83:1838-1843

38. Maxwell SS, Jackson CA, Paternoster L, Cordonnier C, Thijs V, Al-Shahi Salman R, Sudlow CL (2011) Genetic associations with brain microbleeds: Systematic review and meta-analyses. Neurology 77:158-167
39. Nicoll JA, Burnett C, Love S, Graham DI, Dewar D, Ironside JW, Stewart J, Vinters HV (1997) High frequency of apolipoprotein E epsilon 2 allele in hemorrhage due to cerebral amyloid angiopathy. Ann Neurol 41:716-721

40. Yates PA, Sirisriro R, Villemagne VL, Farquharson S, Masters CL, Rowe CC, Group AR (2011) Cerebral microhemorrhage and brain beta-amyloid in aging and Alzheimer disease. Neurology 77:48-54

41. Gurol ME, Dierksen G, Betensky R, Gidicsin C, Halpin A, Becker A, Carmasin J, Ayres A, Schwab K, Viswanathan A, Salat D, Rosand J, Johnson KA, Greenberg SM (2012) Predicting sites of new hemorrhage with amyloid imaging in cerebral amyloid angiopathy. Neurology 79:320-326

\section{Submit your next manuscript to BioMed Central and take full advantage of:}

- Convenient online submission

- Thorough peer review

- No space constraints or color figure charges

- Immediate publication on acceptance

- Inclusion in PubMed, CAS, Scopus and Google Scholar

- Research which is freely available for redistribution

Submit your manuscript at www.biomedcentral.com/submit 